\title{
Identification of cartilage oligomeric matrix protein (COMP) gene mutations in patients with pseudoachondroplasia and multiple epiphyseal dysplasia
}

Received: 6 January 2003/ Accepted: 17 February 2003/Published online: 24 April 2003

(C) The Japan Society of Human Genetics and Springer-Verlag 2003

\begin{abstract}
Mutations in the cartilage oligomeric matrix protein (COMP) gene are responsible for two dominantly inherited skeletal dysplasias, pseudoachondroplasia $(\mathrm{PSACH})$ and multiple epiphyseal dysplasia (MED). Mutation analysis of the COMP gene in Korean patients with PSACH and MED was performed. All nine patients with PSACH had mutations in the COMP gene, while three of the five patients with MED had detectable COMP mutations. Eight mutations, including three novel mutations, were identified in the COMP gene in the patients with PSACH and MED. Six mutations were found within the calmodulin-like repeats (CLRs) domain, especially in the seventh CLR and the other two mutations were in exon 16 outside of CLRs, which encode the C-terminal globular domain. Among the three novel mutations, two were missense mutations (Asp473Tyr, Asp482His) and one was a consecutive two-codon deletion, delAspAsp(469-473) in the five consecutive aspartic acid residues. All three novel mutations produced the PSACH phenotype.
\end{abstract}

Keywords Pseudoachondroplasia $\cdot$ PSACH $\cdot$ Multiple epiphyseal dysplasia $\cdot$ MED $\cdot$ Cartilage oligomeric matrix protein $\cdot \mathrm{COMP} \cdot$ Mutation

The first two authors contributed equally to this work

H.-R. Song · Q.-W. Li

Department of Orthopaedic Surgery,

School of Medicine,

Gyeongsang National University,

Chilam-Dong, Chinju 660-702, Korea

K.-S. Lee · S. K. Koo · S.-C. Jung $(\bowtie)$

Division of Genetic Disease, Department of Biomedical Science,

National Institute of Health, 5 Nokbun-Dong, Eunpyung-Gu,

Seoul 122-701, Korea

E-mail: scjung@nih.go.kr

Tel.: $+82-2-3801534$

Fax: + 82-2-3880924

\section{Introduction}

Pseudoachondroplasia (PSACH; MIM 177170) is a rare dominantly inherited skeletal dysplasia caused by mutations in the cartilage oligomeric matrix protein (COMP; MIM 600310) gene (Briggs et al. 1995; Hecht et al. 1995). It is characterized clinically by short-limb dwarfism, a waddling gait, ligament laxity, and early onset severe osteoarthritis of weight-bearing joints. Some mutations in COMP can lead to a form of multiple epiphyseal dysplasia (MED; MIM 132400), a milder form of the skeletal dysplasia. MED has also been associated with mutations in the genes coding for $\alpha 1, \alpha 2$, and $\alpha 3$ chains of collagen IX, SLC26A2 and matrilin-3 (Chapman et al. 2001; Czarny-Ratajczak et al. 2001).

The predominant features of MED are mild short stature and stiff or painful joints. The phenomenon of overlap between the mild form of PSACH and the severe form of MED has been noticed not only in clinical and radiographic characteristics but also in biochemical findings (Manabe et al. 1998; Stanescu et al. 1993). Therefore, it is now clear that there is a phenotype overlap between these two diseases.

The COMP gene consists of 19 exons and is located on chromosome 19p12-13.1. COMP is a secreted pentameric-adhesive glycoprotein as a member of the thrombospondin family, which is found predominantly in the extracellular matrix of cartilage, tendon, and ligament (Briggs et al. 2002). COMP consists of an $N$-terminal pentameric domain, four epidermal growth factor (EGF)-like domains, and eight calmodulin-like repeats (CLRs). COMP has been shown to bind calcium cooperatively and to interact with collagen I, II and IX with high affinity.

Recently, we studied clinical and molecular characteristics of Korean patients with PSACH. Here we report the COMP gene mutations in patients with PSACH and MED for evaluation of the genotypephenotype relationship. 


\section{Subjects and methods}

Subjects

This study included nine patients with PSACH and three patients with MED, aged from 3 to 33 years (average 20 years). There were five males and seven females. Five patients were young children. Six patients were members of three families, two mother-son relations and two brothers. The diagnoses of these patients were made on the basis of clinical and typical radiographic characteristics by pediatric orthopedic surgeons and a pediatric radiologist.

The patients diagnosed as having pseudoachondroplasia included three children and six adults. The inclusion criteria for pseudoachondroplasia were severe short stature, severe multiplane deformity of the extremities involving the both epiphyses and metaphyses, early onset osteoarthritis, and severe ligament laxity of all the examined joints except for the elbow. The average height of patients older than 17 years with PSACH (6 patients) was $116.3 \mathrm{~cm}$. All patients showed normal intelligence and nearly normal head and face physiology. The patients diagnosed as having multiple epiphyseal dysplasia included two children and one adult. The inclusion criteria for multiple epiphyseal dysplasia were mild short stature, mild deformity of the extremities involving only the epiphysis, early onset osteoarthritis, and no joint hypermobility. Two children were brothers and were below the third percentile for height. The height of one adult (patient 3) was $140 \mathrm{~cm}$.

Mutation analysis

Informed consents for DNA analysis were obtained from the patients and/or their parents, depending on patient's age. Genomic DNA was isolated from peripheral blood leukocytes using the QIAamp DNA blood kit, following the manufacturer' instructions (Qiagen, Hilden, Germany). All 19 exons of the COMP gene, including exon-intron boundaries, were amplified by PCR. PCR amplicons were extracted from an agarose gel using gel extraction kit (Qiagen). Direct sequencing was performed using a BigDye Terminator Cycle Sequencing Ready Reaction kit, version 2.0 (PE Applied Biosystems, Foster City, CA, USA) and analyzed with an ABI 310 automated sequencer (PE Applied Biosystems) according to the standard methods. To clarify heterozygous deletion mutations of the trinucleotide repeats region in exon 13, PCR products were subcloned into pGEM-T Easy Vector (Promega, WI, USA) and subjected to sequencing analysis. In addition, COMP genes in 50 normal individuals were analyzed to confirm that the novel sequence variations in the COMP gene revealed in this study were not polymorphisms but real pathogenic mutations.

\section{Results}

All nine patients with PSACH had mutations in the COMP gene, while only three of the five patients with
MED had detectable COMP mutations. Eight mutations were identified in the COMP gene in the twelve patients with PSACH or MED (Table 1). Three mutations were shown in the family members. All mutations were heterozygous. Six mutations were found within the CLRs, especially in the seventh CLR, and the other two mutations were in exon 16 outside of CLRs, which encode the C-terminal globular domain. Three mutations were newly identified mutations in this study. Two were missense mutations (Asp473Tyr, Asp482His; Fig. 1A-B) and the other mutation was a consecutive two-codon deletion, delAspAsp(469-473), in the five consecutive aspartic acid residues (Fig. 2).

\section{Discussion}

PSACH and MED are autosomal dominantly inherited skeletal dysplasias caused by heterozygous mutations in the COMP gene. The majority of identified COMP mutations are clustered in the type III repeat (Briggs et al. 2002), most localized to conserved residues within the CLRs encoded by exons 8-14. Eight mutations, including three novel mutations, were identified in this study. Two mutations were observed in the MED phenotype and six in the PSACH. For the Thr585Met mutation, there were two reports concerning their produced phenotype. In one report (Briggs et al. 1998), the patient with the Thr585Met mutation produced the PSACH phenotype, in the other report (Czarny-Ratajczak et al. 2001), the patient with Thr585Met produced the MED phenotype, which was the same as our observation. The Asp385Asn mutation was a recently identified mutation (Mabuchi et al. 2003), which produced the MED phenotype. The Asp385Asn mutation was shared in two brothers, which was supposed to be a germline mutation, because their parents had no symptoms of skeletal dysplasia.

About one-third of the patients with PSACH carried a deletion of one codon in a short GAC repeat which encodes aspartic acid residues 469-473 (Hecht et al. 1995; Briggs et al. 1998). We identified a novel consecutive twocodon deletion, delAspAsp(469-473), resulting in the contraction of the repeat unit to three GAC repeats, $(\mathrm{GAC})_{3}$. This novel deletion mutation, delAspAsp(469473), was inherited from mother to son. A novel missense
Table 1 Identification of mutations in the COMP gene of each patient

MED multiple epiphyseal dysplasia, PSACH pseudoachondroplasia

${ }^{\text {a }}$ Standard deviation

${ }^{\mathrm{b}}$ Novel mutations identified in this study

\begin{tabular}{cllllll}
\hline No. & Sex/age & Diagnosis & Height $\left(\mathrm{cm} / \mathrm{SD}^{\mathrm{a}}\right)$ & Mutation & Domain (Exon) & Relation \\
\hline 1 & $\mathrm{M} / 13$ & MED & $153 /-0.4$ & D385 N & CLR4 (11) & Brother \\
2 & $\mathrm{M} / 11$ & MED & $140 /-0.7$ & D385 N & CLR4 (11) & Brother \\
3 & $\mathrm{~F} / 23$ & MED & $140 /-4.5$ & T585 M & C-term (16) & \\
4 & $\mathrm{~F} / 35$ & PSACH & $125 /-8.3$ & C328R & CLR2 (10) & Mother \\
5 & $\mathrm{M} / 9$ & PSACH & $103 /-6.6$ & C328R & CLR2 (10) & Son \\
6 & $\mathrm{~F} / 17$ & PSACH & $107 /-11.1$ & DelD $(469-473)$ & CLR7 (13) & \\
7 & $\mathrm{~F} / 34$ & PSACH & $103 /-13.8$ & DelD $(469-473)$ & CLR7 (13) & \\
8 & $\mathrm{~F} / 36$ & PSACH & $125 /-8.3$ & DelDD(469-473) & CLR7 (13) & Mother \\
9 & $\mathrm{M} / 3$ & PSACH & $83 /-3.5$ & DelDD $(469-473)^{\mathrm{b}}$ & CLR7 (13) & Son \\
10 & $\mathrm{M} / 25$ & PSACH & $117 /-11.7$ & D473Y & CLR7 (13) & \\
11 & $\mathrm{~F} / 26$ & PSACH & $121 /-9.3$ & D482H & CLR8 (13) & \\
12 & $\mathrm{~F} / 8$ & PSACH & $91 /-7.0$ & H587R & C-term (16) & \\
\hline
\end{tabular}


A
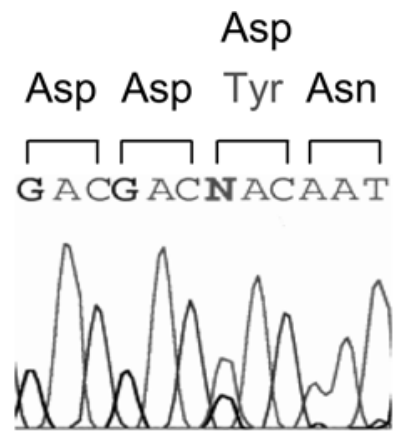

$\mathrm{B}$

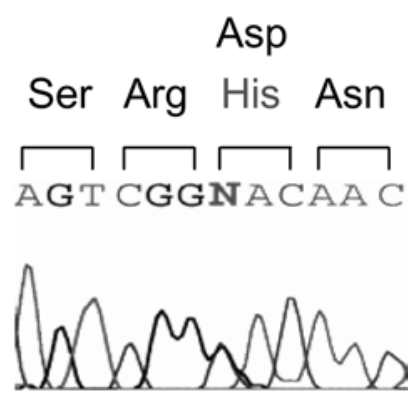

Fig. 1 Direct sequencing results demonstrate novel heterozygous missense mutations. A Heterozygous $G$ to $T$ transversion within exon 13, resulting in an Asp473Tyr missense mutation. B Heterozygous $\mathrm{G}$ to $\mathrm{C}$ transversion within exon 13 , resulting in Asp482His

mutation, Asp473Tyr, also was identified, which affects the fifth aspartic acid of residues. Usually, heterozygosity for the $(\mathrm{GAC})_{4}$ and $(\mathrm{GAC})_{7}$ produced the PSACH phenotype, while heterozygosity for the (GAC) 6 alleles resulted in the milder MED phenotype (Délot et al. 1999). In our observation, the patients with heterozygosity for the codon deletions, delAsp(469-473), delAspAsp(469473), and the patient with heterozygosity for the missense mutation (Asp473Tyr) in the seventh CLR of COMP gene produced the PSACH phenotype. The calmodulinlike domain of COMP is composed of the consensus sequence DXDXDX8 (Maddox et al. 1997), in the seventh CLR, the DXDXD sequence is the stretch of five consecutive aspartic acids. Another common point mutation, Asp472Tyr, which affects this stretch also has been reported to produce PSACH mutation (Briggs et al. 2002). Another novel Asp482His mutation was identified in the COMP gene from the patient with PSACH. The Cys328Arg mutation was inherited from mother to son with the PSACH phenotype.

Patients with mutations in exon 13 were significantly short, relative to those with mutations elsewhere in the COMP gene $(p=0.046)$. The heights of patients with mutations in exon 13 were below $-8 \mathrm{SD}$, with one exception of a 3-year old patient with PSACH. In accordance with our observations, the recent paper of Mabuchi et al. reported that patients with mutations in the seventh CLR were very short relative to those with
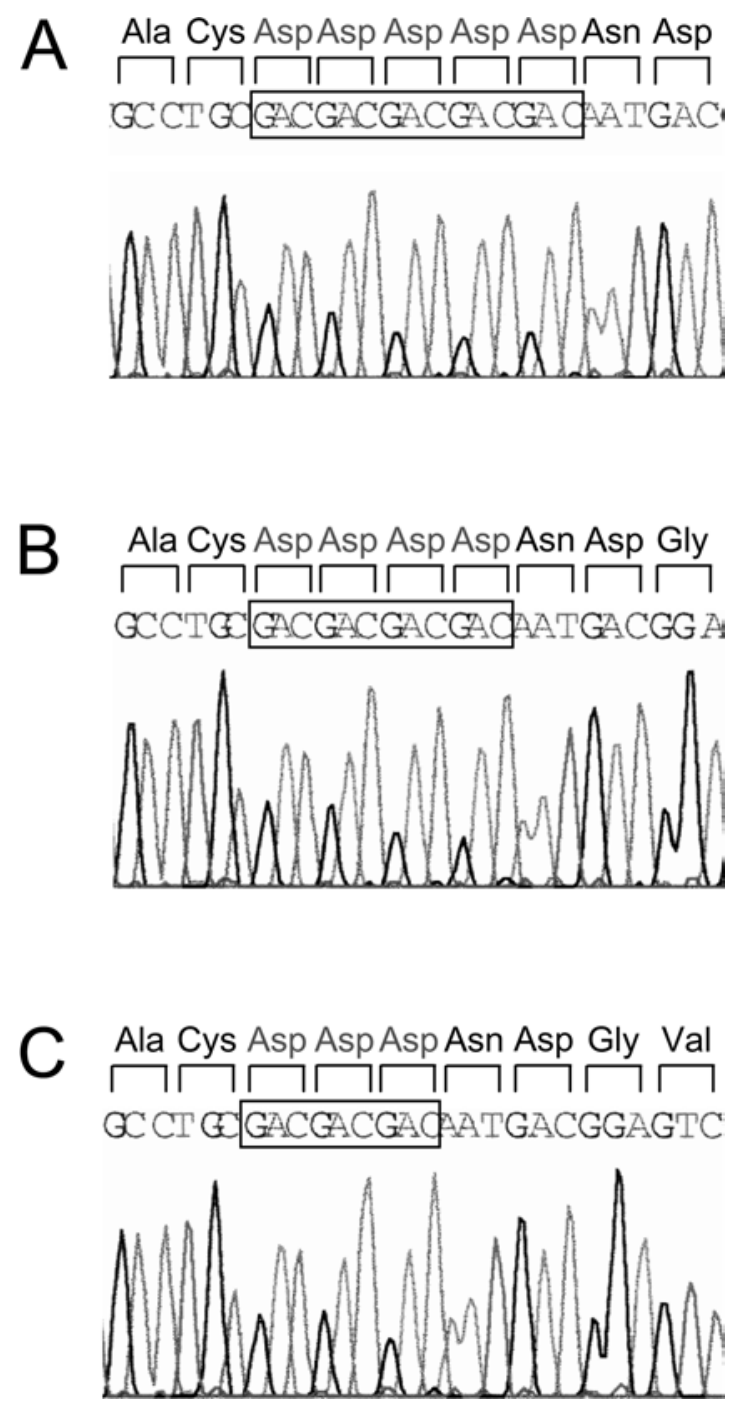

Fig. 2 Deletion mutations of trinucleotide repeats region in exon 13. A Normal sequence allele. B One codon (GAC) deletion results in delD(469-473). C Newly identified consecutive two-codon (GACGAC) deletion results in delDD(469-473). Heterozygous deletion alleles were subcloned into the pGEM-T Easy Vector (Promega) and subjected to sequencing analysis

mutations on other CLRs or elsewhere in the COMP gene (Mabuchi et al. 2003).

Further studies of the COMP gene mutation and observations of the genotype-phenotype relationship will be very helpful for elucidating COMP gene function and the pathogenesis of PSACH and MED.

Acknowledgements The authors thank the members of Little People of Korea (http://www.lpk.co.kr) for the contribution and cooperation in this research.

\section{References}

Briggs MD, Hoffman SMG, King LM, Olsen AS, Mohrenweiser H, Leroy JG, Mortier GR, Rimoin DL, Lachman RS, Gaines ES, Cekleniak JA, Knowlton RG, Cohn DH (1995) Pseudoa- 
chondroplasia and multiple epiphyseal dysplasia due to mutations in the cartilage oligomeric matrix protein gene. Nat Genet 10:330-336

Briggs MD, Mortier GR, Cole WG, King LM, Golik SS, Bonaventure J, Nuytinck L, De Paepe A, Leroy JG, Biesecker L, Lipson M, Wilcox WR, Lachman RS, Rimoin DL, Knowlton RG, Cohn DH (1998) Diverse mutations in the gene for cartilage oligomeric matrix protein in the pseudoachondroplasiamultiple epiphyseal dysplasia disease spectrum. Am J Hum Genet 62:311-319

Briggs MD, Chapman KL (2002) Pseudoachondroplasia and multiple epiphyseal dysplasia: Mutation review, molecular interactions, and genotype to phenotype correlations. Hum Mutat 19:465-478

Chapman KL, Mortier GR, Chapman K, Loughlin J, Grant ME, Briggs MD (2001) Mutations in the region encoding the von Willebrand factor A domain of matrilin-3 are associated with multiple epiphyseal dysplasia. Nat Genet 28:393-396

Czarny-Ratajczak M, Lohiniva J, Rogala P, Kozlowski K, Perala M, Carter L, Spector TD, Kolodziej L, Seppanen U, Glazar R, Krolewski J, Latos-Bielenska A, Ala-Kokko L (2001) A mutation in COL9A1 causes multiple epiphyseal dysplasia: further evidence for locus heterogeneity. Am J Hum Genet 69:969-980

Délot E, King LM, Briggs MD, Wilcox WR, Cohn DH (1999) Trinucleotide expansion mutations in the cartilage oligomeric matrix protein (COMP) gene. Hum Mol Genet 8:123-128
Hecht JT, Nelson LD, Crowder E, Wang Y, Elder FFB, Harrison WR, Francomano CA, Prange CK, Lennon GG, Deere M, Lawler J (1995) Mutations in exon 17B of cartilage oligomeric matrix protein (COMP) cause pseudoachondroplasia. Nat Genet 10:325-329

Mabuchi A, Manabe N, Haga N, Kitoh H, Ikeda T, Kawaji H, Tamai K, Hamada J, Nakamura S, Brunetti-Pierri N, Kimizuka M, Takatori Y, Nakamura K, Nishimura G, Ohashi H, Ikegawa S (2003) Novel types of COMP mutations and genotype-phenotype association in pseudoachondroplasia and multiple epiphyseal dysplasia. Hum Genet 112:84-90

Manabe N, Nakamura K, Ikegawa S. Kimizuka M. (1998) A mild form of pseudoachondroplasia: minimal epi-metaphyseal involvement of long bones. Eur J Radiology 28:155-159

Maddox BK, Keene DR, Sakai LY, Charbonneau NL, Morris NP, Ridgway CC, Boswell BA, Sussman MD, Horton WA, Bachinger HP, Hecht JT (1997) The fate of cartilage oligomeric matrix protein is determined by the cell type in the case of a novel mutation in pseudoachondroplasia. $\mathrm{J}$ Biol Chem 272:30993-30997

Stanescu R, Stanescu V, Muriel MP, Maroteaux P (1993) Multiple epiphyseal dysplasia, Fairbank type. Morphologic and biochemical study of cartilage. Am J Med Genet 45:501-507 